\title{
Anatomy of corpus callosum in prenatally malnourished rats
}

\author{
Ricardo Olivares ${ }^{1 *}$, Carlos Morgan ${ }^{2}$, Hernán Pérez ${ }^{2}$, Alejandro Hernández ${ }^{3}$, Francisco Aboitiz ${ }^{4}$, Rubén Soto- \\ Moyano ${ }^{2}$, Julio Gil ${ }^{5}$, Alexis Ortiz ${ }^{6}$, Osvaldo Flores ${ }^{2}$, Miguel Gimeno ${ }^{5}$ and Jesús Laborda ${ }^{5}$ \\ ${ }^{1}$ Departamento de Ciencias Biológicas Animales, Facultad de Ciencias Veterinarias y Pecuarias, Universidad de Chile. \\ ${ }^{2}$ Laboratorio de Nutrición y Regulación Metabólica, Instituto de Nutrición y Tecnología de los Alimentos, Universidad de Chile. \\ ${ }^{3}$ Departamento de Biología, Facultad de Química y Biología, Universidad de Santiago Chile. \\ ${ }^{4}$ Departamento de Psiquiatría, Escuela de Medicina y Centro Interdisciplinario de Neurociencia, Pontificia Universidad Católica de Chile \\ ${ }^{5}$ Departamento de Anatomía, Embriología y Genética Animal, Facultad de Veterinaria, Universidad de Zaragoza, España. \\ ${ }^{6}$ Universidad Andrés Bello, Facultad de Ecología y Recursos Naturales, Av. República 252, Santiago.
}

\begin{abstract}
The effect of prenatal malnutrition on the anatomy of the corpus callosum was assessed in adult rats (45-52 days old). In the prenatally malnourished animals we observed a significant reduction of the corpus callosum total area, partial areas, and perimeter, as compared with normal animals. In addition, the splenium of corpus callosum (posterior fifth) showed a significant decrease of fiber diameters in the myelinated fibers without changing density. There was also a significant decrease in diameter and a significant increase in density of unmyelinated fibers. Measurements of perimeter's fractal dimensions from sagittal sections of the brain and corpus callosum did not show significant differences between malnourished and control animals. These findings indicate that cortico-cortical connections are vulnerable to the prenatal malnutrition, and suggest this may affect interhemispheric conduction velocity, particulary in visual connections (splenium).
\end{abstract}

Key Words: corpus callosum, prenatal malnutrition, rat, splenium

\section{INTRODUCTION}

A commonly used protocol for inducing prenatal malnutrition in rats consists of a restriction of food intake in pregnant females at a $40 \%$ of daily requirements since the eighth day of pregnancy up to birth (Soto-Moyano et al., 1993). This and other types of caloric-protein malnutrition of pregnant rats correlate with lower body weight of the offspring as well as with a high mortality rate during early postnatal life (Morgane et al., 1993).

In humans, fetal undernutrition has been found to be associated to disease in a variety of physiological systems, such as the cardiovascular system (hypertension, coronary heart disease, stroke, atherosclerosis, coagulation disorders, preeclampsia), reproductive system (polycystic ovary syndrome, early adrenarche/menarche, early menopause), respiratory system (chronic obstructive pulmonary disease, asthma), endocrine system (hypercortisolism, hypothyroidism), skeletal system (osteoporosis), and the nervous system (neurological disorders, schizophrenia, dementia) (for review see Fowden et al. 2006). In animal models of experimental malnutrition (rat, guinea pig and sheep), changes in the fetal nutritional environment lead to permanent alterations of the developmental pattern of cellular proliferation and differentiation in key tissue and organ systems (hearth, endothelium, vascular smooth muscle, skeletal muscle, kidney, rennin-angiotensin system, pancreatic growth, adipose tissue and adipocyte secretion, hypothalamo-pituitary-adrenal axis, and peripheral and central nervous system) that results in pathological consequences in adult life (for review see McMillen and Robinson, 2006).

Concerning the rat central nervous system, prenatal malnutrition has been shown to alter brain development and growth, thus desynchronizing cell migration, retarding or blocking cell differentiation and increasing cell death associated to a diminished number of neurons (Morgane et al., 1993). Those impairments are frequently associated to behavioral alterations (Morgane et al., 1993; Levitsky and Strupp, 1995). In addition, inadequate prenatal nutrition increases central noradrenaline levels and release (SotoMoyano et al., 1994; Soto-Moyano et al., 1998a; Soto-Moyano et al., 1998b), which is most relevant because noradrenaline is a critical factor for regulating regressive events of neuronal projections during normal brain development (Soto-Moyano et al., 1994).

The corpus callosum (CC) is the major commissure in the brain of placental mammals, being formed by numerous transversal fibers connecting mostly homologous but also heterologous cortical areas in both hemispheres (Aboitiz et al., 1993). Its function is to integrate sensory and cognitive experience of the two sides of the brain and is a likely target of developmental injuries. In fact, the CC and total brain size are affected by prenatal insults like ethanol ingestion and overt protein malnutrition (Morgane et al., 1978; Zimmerberg and Mickus 1990; Gressens et al., 1997). Overt prenatal protein malnutrition also reduces spontaneous forebrain neuronal activity in adulthood (Stern et al., 1983). Moreover, projecting fields of transcallosal evoked responses are affected in overt and hidden forms of prenatal protein malnutrition (SotoMoyano et al., 1993; Soto-Moyano et al., 1998a; Forbes et al., 1975). Although reduction in CC size and functionality has been reported in malnourished animals, it has not yet been studied at the fine anatomical and ultrastructural levels.

On these bases, it seems likely that the CC may be an important target in the pathophysiology of prenatal 
malnutrition. In order to assess this hypothesis, the effect of prenatal malnutrition on CC anatomy was determined in adult rats (45-52-day old). The perimeter, total area and partial areas of CC sagittal cuts, as well as the fractal dimension of CC shape were determined. In addition, we considered of interest to study the possible effects of malnutrition on the histology of the callosal splenium, which may affect the velocity of corticalcortical occipital conduction, and particularly the visual information.

\section{METHODS}

\section{Laboratory Animals and Experimental Treatment}

The experimental protocols and animal management were carried out in accordance to NIH guidelines (NIH, 1996) and approved by the Committee of Bioethics at INTA, University of Chile. The experiments were conducted on male and female Sprague-Dawley rats (INTA, Santiago, Chile) born from dams subjected during pregnancy to one of the following nutritional conditions (8 pregnant rats per groups): 1) well-nourished pregnant rats, with free access to a $21 \%$ protein non purified diet (Champion ${ }^{\circledR}$, Santiago, Chile: $21.4 \%$ protein, $6.9 \%$ fat, $45.9 \%$ carbohydrate, $4.6 \%$ minerals, $0.5 \%$ vitamins, $10 \%$ water, $10.7 \%$ non-nutritive filler and $13.3 \mathrm{KJ} / \mathrm{g}$. ) (Soto-Moyano et al., 1998b), and 2) malnourished pregnant rats, with free access to food until 7 days post-conception; after this date the nonpurified diet was restricted to $10 \mathrm{~g} /$ day until parturition. This amount of food is about $40 \%$ of that consumed by normal pregnant rats during weeks 2 and 3 of gestation (Soto-Moyano et al., 1993; Soto-Moyano et al., 1998b), and was given two times daily ( $5 \mathrm{~g}$ at 09:00 $\mathrm{h}$ and $5 \mathrm{~g}$ at 19:00h) in order to minimize anxiety for feeding in food restricted pregnant dams. At birth, to ensure adequate nutrition during lactation, prenatally malnourished pups were fostered to well-nourished dams giving birth on that day, according to rearing procedures already described (Morgane et al., 1993); pups born from well-nourished mothers were also fostered to well-nourished dams, in order to equalize among groups other factors that may depend on the rearing conditions (i.e. stress due to crossfostering) (Navarrete et al., 2007).

During the suckling period, all litters were adjusted to 8 pups per dam (4 males and 4 females), and all dams continued to receive the standard laboratory diet ad libitum. After weaning at 21 days of age, the offspring were given free access to the nonpurified diet up to sacrifice (45-52 days of age). Body weight of pregnant rats and offspring were measured daily. All these procedures were performed as previously reported (SotoMoyano et al., 1993; Soto-Moyano et al., 1998b).

\section{Macroscopic study}

After i.p. injection of $40 \mathrm{mg} / \mathrm{kg}$ sodium thiopental and intracardial perfusion of $10 \%$ formalin in saline solution, at body temperature and at equivalent volume

of $20 \%$ to body weight, animals (malnourished $=8$ and control $=8$ ) were sacrificed by decapitation. Encephala were extracted and kept in 10\% formalin until sectioned and photographed. Digital photographs of mid-sagittal sections were analyzed using the software Scion Image for Windows (Merlo et al., 2002), under 100X total magnification, to determine total and partial areas of CC as well as perimeters, according to Witelson
(1989), who divided arbitrarily the corpus callosum into three regions in relation to its maximum length: the anterior third (genu), the middle third (body), and the posterior third which is often divided into fifth posterior (splenium) (Fig. 1). Brain weight measurements were performed excluding cerebellum, brainstem and olfactory bulbs.

We calculated the fractal dimension of the perimeters of $\mathrm{CC}$ areas with the FDC (Fractal Dimension Calculator) software, which uses the box-counting technique. The math formula used for calculations is $\log \mathrm{N}(\mathrm{s})=\mathrm{D} \log (1 / \mathrm{s})$, where: $\mathbf{D}$ is fractal dimension, $\mathbf{N}$ is the number of boxes containing image dots, and $\mathbf{s}$ is the box side iterated as expressed in pixels (Guzmán et al., 1993). Mathematicians have demonstrated that fractal dimension could be used to measure the space complexity of a structure, the greatest values of fractal dimensions being associated to high geometric complexity of any structure. We made the calculations over the perimeter of the problem zone from original images filtered by Photoshop software. From these images we calculated the fractal dimensions. Thereafter, we compare the fractal dimension of sagittal cuts from brain and corpus callosum from eutrophic and malnourished groups (Fig. 1).

Microscopy study

Eight animals and their respective controls were perfused transcardially with Karnosky's solution $(1.5 \%$ glutaraldehyde; $0.8 \%$ paraformaldehyde) in sodium phosphate buffer, at body temperature and at equivalent volumen of $20 \%$ to body weight. Thereafter the brain was extracted and the splenium of CC (posterior fifth) dissected, which contains visual fibers from the occipital cortex and other regions (Witelson, 1989). Tissues were fixed in $2.5 \%$ glutaraldehyde for $8 \mathrm{~h}$ at $4{ }^{\circ} \mathrm{C}$ and afterward washed in $0.1 \mathrm{M}$ sodium phosphate buffer, $\mathrm{pH}$ 7.3. Tissue samples were post-fixed in $1 \%$ osmium tetroxide for 1 $\mathrm{h}$ at room temperature, and finally included in EPON. Semithin $1 \mu \mathrm{m}$ slices were obtained and stained with toluidine blue in $1 \%$ sodium borate to show the splenium (posterior region), allowing axons to be counted (expressed as number of axons per $\mathrm{mm}^{2}$ ) and diameters of both myelinated and non-myelinated callosal fibers measured (expressed in $\mu \mathrm{m}$ ). Thereafter, $60 \mathrm{~nm}$ thin slices were mounted on 200 mesh grids, and left in uranyl acetate and Reynolds stain for $10 \mathrm{~min}$, before observing them at the transmission electron microscope

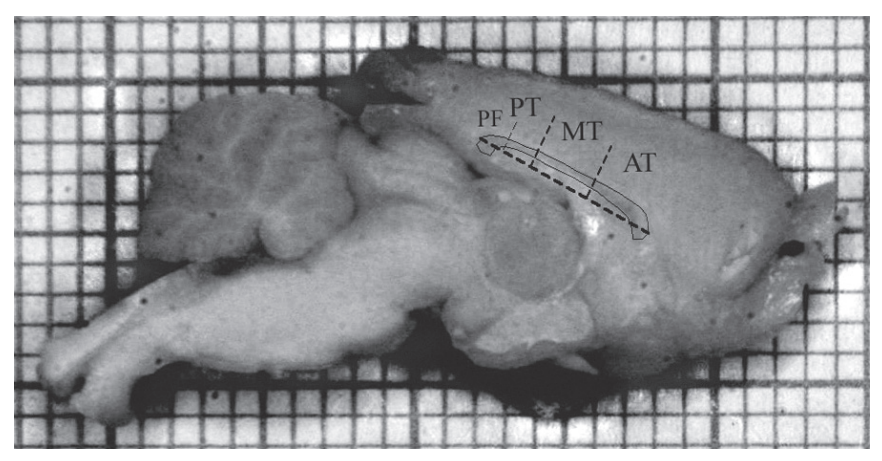

Figure 1: Cross section of corpus callosum indicating the three regions and posterior fifth in relation to its maximum length. AT $=$ anterior third, $\mathrm{MT}=$ middle third, $\mathrm{PT}=$ posterior third, and $\mathrm{PF}=$ posterior fifth. Each square in the background is of $1 \mathrm{~mm}$ side 
(Zeiss EM 109). Observations were made at an adequate magnification to get a clear visualization of myelinated and unmyelinated axons. Five of ten fields $(27,000 \times 23,000$ $\mu \mathrm{m})$ were photographed per every splenium respective to each animal, and analyzed with the software Scion Image for Windows (Merlo et al., 2002; Olivares et al., 2007) using total magnification of $28,606 \mathrm{X}$. All fibers were counted excepting those touching the left and inferior adjacent sides and the lower right of the images (Gundersen, 1977). An average number of 109 myelinated and 593 unmyelinated fibers were counted per field. Regarding the myelinated fibers, their internal diameters were considered excluding the myelin sheat, and considering the minimal diameter of every fiber, in order to minimize factors such as elongation of the tissue and oblique cutting of fibers. Glial processes cannot not distinguished from unmyelinated fibers with the panoramic magnification used for fiber counting; however, these processes are more frequent between adjacent myelinated fibers, regions that were not considered in the counting process.

\section{Statistical analysis}

Resulting values from malnourished $(\mathrm{n}=8)$ and control animals $(\mathrm{n}=8)$, were corrected at their real magnification, and data are reported as means $\pm \mathrm{SD}$.

We used the Program SPSS (Statistical Package for the Social Sciences) from IBM ${ }^{\circledR}$ SPSS ${ }^{\circledR}$ Statistics. The statistic Mann-Whitney U test (Ferrán, 2001) is a nonparametric test that we used to determine the effect of diet on the performed measurements. We used it because it is a distribution free test or nonparametric one, then does not require assumptions about the shape of the underlying compared distributions. It tests the hypothesis that two independent samples come from populations having the same distribution, statistical differences were considered significant at a probability level equal or less than 0.05 .

\section{RESULTS}

The macroscopic study showed that the offspring of malnourished dams presented lower body weight than eutrophic animals since birth up to weaning ( $<0.001)$, but no differences were observed when sacrificed at adulthood (45-52 days of age). Nevertheless, malnourished animals exhibited lower brain weight at the moment of sacrifice $(p<0.01)$ as compared to control animals. Additionally, we calculated the percentage of weight gain of malnourished animals respective to eutrophic controls, from birth to weaning and from weaning to sacrifice. In the first case there was a decrease in weight gain $(\mathrm{p}<0.01)$ and in the latter case an increase $(\mathrm{p}<0.01)$. Finally, the difference between brain weight/body weight ratios between the two groups was not significant (Table I).

Regarding the total and partial areas of $\mathrm{CC}$, a reduction was observed in the malnourished group $(\mathrm{p}<0.05)$ as well as in total perimeter $(\mathrm{p}<0.01$; Table II) as compared to controls. No significant statistical differences were detected when comparing fractal dimension of brain and CC from malnourished and control animals (Table III) using MannWhitney U test statistics.

TABLE I

Average body weight, brain weight, gain weight and brain:body weight relation

\begin{tabular}{|c|c|c|c|}
\hline WEIGHTS & Malnourished $(\mathrm{n}=8)$ & Control $(n=8)$ & M-W U Test \\
\hline Body weight at birth (g) & $6.06 \pm 0.14$ & $7.55 \pm 0.24$ & $\mathrm{p}<0.001$ \\
\hline Body weight at weaning (g) & $42.69 \pm 1.28$ & $59.35 \pm 3.19$ & $\mathrm{p}<0.001$ \\
\hline Body weight 45-52-day-old (g) & $154.50 \pm 18.88$ & $170.64 \pm 22.00$ & NS \\
\hline Weight gain from birth to weaning (\%) & $604.58 \pm 30.12$ & $686.67 \pm 46.34$ & $\mathrm{p}<0.01$ \\
\hline Weight gain from weaning to sacrifice (\%) & $261.63 \pm 39.62$ & $187.38 \pm 31.95$ & $\mathrm{p}<0.01$ \\
\hline Brain weight $(\mathrm{g})$ & $1.10 \pm 0.07$ & $1.23 \pm 0.06$ & $\mathrm{p}<0.01$ \\
\hline Brain: Body weight relation & $0.73 \pm 0.07$ & $0.73 \pm 0.09$ & NS \\
\hline
\end{tabular}

TABLE II

Average callosal measurements

\begin{tabular}{lccc}
\hline CALLOSAL MEASUREMENTS & Malnourished $(\mathrm{n}=8)$ & Control $(\mathrm{n}=8)$ & M-W U Test \\
\hline Total area $\left(\mathrm{mm}^{2}\right)$ & $2.65 \pm 0.61$ & $3.93 \pm 0.31$ & $\mathrm{p}<0.01$ \\
Anterior third $\left(\mathrm{mm}^{2}\right)$ & $0.95 \pm 0.22$ & $1.49 \pm 0.3$ & $\mathrm{p}<0.01$ \\
Middle third $\left(\mathrm{mm}^{2}\right)$ & $0.74 \pm 0.26$ & $1.08 \pm 0.16$ & $\mathrm{p}<0.05$ \\
Posterior third $\left(\mathrm{mm}^{2}\right)$ & $0.97 \pm 0.17$ & $1.36 \pm 0.24$ & $\mathrm{p}<0.01$ \\
Posterior fifth $\left(\mathrm{mm}^{2}\right)$ & $0.62 \pm 0.13$ & $0.87 \pm 0.14$ & $\mathrm{p}<0.01$ \\
Total perimeter $(\mathrm{mm})$ & $14.54 \pm 1.37$ & $17.13 \pm 1.29$ & $\mathrm{p}<0.01$ \\
\hline
\end{tabular}

TABLE III

Average fractal dimensions

\begin{tabular}{|c|c|c|c|}
\hline FRACTAL DIMENSION & Malnourished $(n=8)$ & Control $(n=8)$ & M-W U Test \\
\hline Brain & $1.08 \pm 0.03$ & $1.09 \pm 0.02$ & NS \\
\hline Corpus callosum & $1.35 \pm 0.09$ & $1.29 \pm 0.07$ & NS \\
\hline
\end{tabular}


The CC of malnourished rats exhibited thinner myelinated fiber diameters than the control group $(\mathrm{p}<0.05)$. In addition, the malnourished group also presented lower values in the diameter of unmyelinated fibers than the control group $(\mathrm{p}<$ 0.001; Table IV, Fig. 2 and 3). Density of myelinated fibers was not different between groups. In contrast, malnourished rats presented higher density of unmyelinated fibers than controls ( $<<0.05$; Table V, Fig. 2 and 3).

\section{DISCUSSION}

Macroscopic study

Malnutrition during gestation resulted in a significant body weight deficit of pups at birth and at weaning age, and in significantly less weight gain from birth to weaning, indicating that reduction of food intake by the dams during pregnancy caused fetal growth retardation. Although the weight gain from weaning to sacrifice was significant higher in the malnourished group, no differences were observed in body weight of young rats at sacrifice and in the brain/body weight

TABLE IV

Average diameter fibers

\begin{tabular}{lccc}
\hline$\mu \mathrm{m}$ & $\begin{array}{c}\text { Malnourished } \\
(\mathrm{n}=8)\end{array}$ & $\begin{array}{c}\text { Control } \\
(\mathrm{n}=8)\end{array}$ & M-W U Test \\
\hline Myelinated Fibers & $0.42 \pm 0.03$ & $0.49 \pm 0.07$ & $\mathrm{p}<0.05$ \\
Unmyelinated Fibers & $0.12 \pm 0.01$ & $0.18 \pm 0.02$ & $\mathrm{p}<0.001$ \\
\hline
\end{tabular}

TABLE V

Average density fibers

\begin{tabular}{lccc}
\hline axons $/ \mathrm{mm}^{2}$ & $\begin{array}{c}\text { Malnourished } \\
(\mathrm{n}=8)\end{array}$ & $\begin{array}{c}\text { Control } \\
(\mathrm{n}=8)\end{array}$ & M-W U Test \\
\hline Myelinated Fibers & $0.19 \pm 0.04$ & $0.16 \pm 0.02$ & NS \\
Unmyelinated Fibers & $1.18 \pm 0.29$ & $0.73 \pm 0.24$ & $\mathrm{p}<0.05$ \\
\hline
\end{tabular}

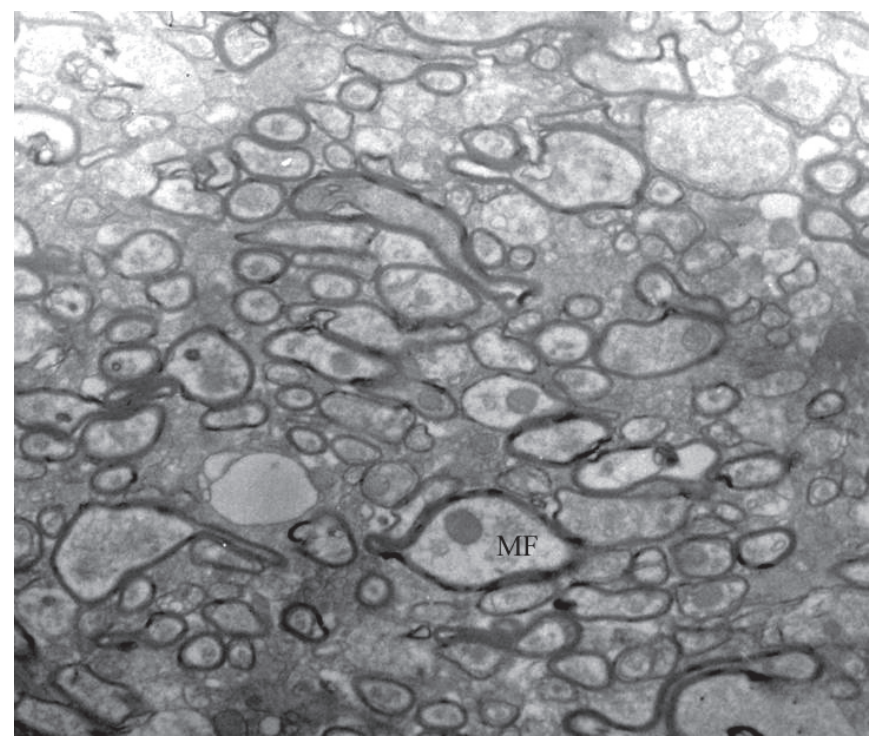

Figure 2: Electron micrograph of the splenium from a representative control animal. MF: myelinated fiber, Bar: $1 \mu \mathrm{m}$. relation, which is in agreement with previous works by our group (Soto-Moyano et al., 1998a; Soto-Moyano et al., 1998b; Navarrete et al., 2007). Malnutrition during gestation also resulted in a significant brain weight deficit in newborns (Table I). The postnatal recuperation of body weight, but not of brain weight, complies with the concept of a prenatal correlated growth between body and brain that becomes unlocked postnatally, body weight then increasing much faster than brain weight (Aboitiz, 1996).

Our findings regarding the CC are in agreement with Zimmerberg and Mickus (1990), who investigated the size of CC in rats prenatally exposed to alcohol. Those animals exhibited smaller total CC areas than control animals and the callosal size was negatively correlated to open field activity, suggesting a possible role in normal exploratory behavior. Furthermore, in a previous work from our group, rats malnourished prenatally and during lactation with a low-protein, isocaloric diet were shown to have smaller CC than controls, which was consistent with differences in brain weight. In contrast, prenatally malnourished rats rehabilitated with high-protein diet during lactation showed normal brain weight and development of the mid-third and posterior third of the callosum, but reduced size of the anterior third at 45-52 days of age (Olivares et al., 2002). This observation may imply that those rehabilitated animals are specifically damaged in certain frontal functions (Kolb, 1984). In our current study the experimental conditions were more dramatic, since all partial areas of CC were significantly smaller $(p<0.05)$ in malnourished than in control animals (Table II). These results suggest that prenatal malnutrition affects interhemispheric connections in different regions of the cerebral cortex.

We used the same morphometric software utilized by Merlo et al., (2002) who found changing values of callosal areas and perimeters with age in humans with no significant differences between genders. We used the Box counting technique to calculate fractal dimensions, as previously used in works on kidney (Gil et al., 2006) and the bronchial tree (Canals et al.,

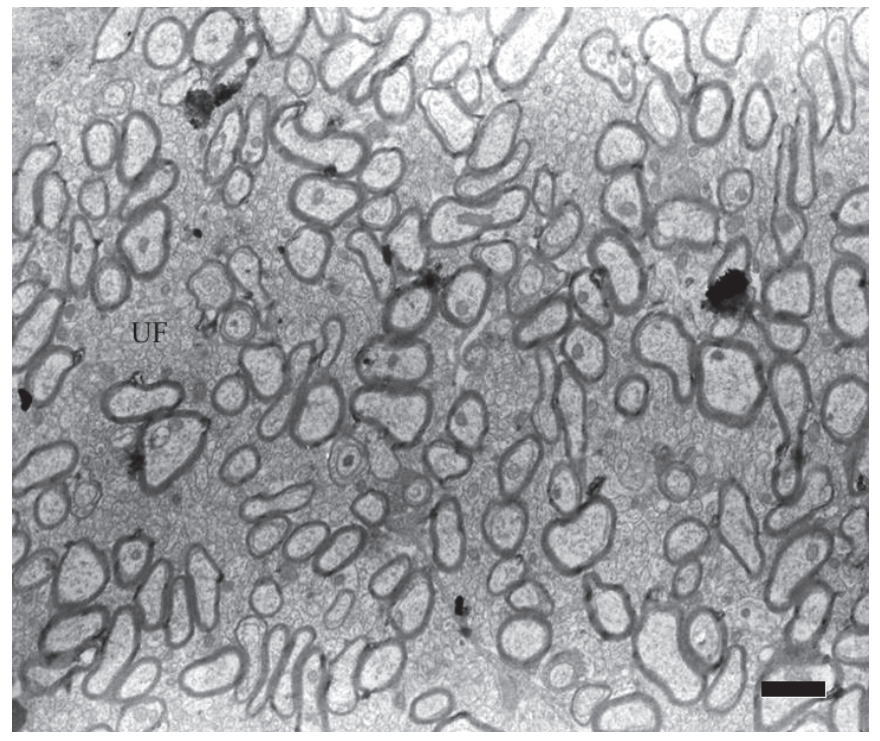

Figure 3: Electron micrograph of the splenium from a representative malnourished animal. UF: unmyelinated fiber, Bar: $1 \mu \mathrm{m}$. 
2003). We have not found previous works showing calculations of CC fractal dimension. Kiselev et al., (2003) determined fractal dimension of the whole cerebral cortex by a volumetric method from data obtained by magnetic resonance imaging, a different methodology than that used by us.

Microscopic Study

Diverse factors can affect the normal histology of CC. For example, the effects of alcohol consumption as well as thiamin deficiency on CC size have been studied in rats (He et al., 2007). When examined at the electron microscopy, the CC from those animals showed thinner diameters, higher fiber density, a high proportion of small diameter fibers and thinner myelin sheaths than groups ingesting either alcohol-thiamin or waterthiamin (He et al., 2007).

Concerning the reported inverse relationship between axon diameter and density (Aboitiz, 1992), our data showed that the callosal splenium evidenced a significant decrease in diameters in both myelinated and unmyelinated fibers ( $p$ $<0.05 ; \mathrm{p}<0.001$, respectively) and an increase of density of unmyelinated fibers in malnourished animals ( $\mathrm{p}<0.05)$, but not of myelinated fibers (Fig. 2 and 3). These observations are in line with previous studies in rats subjected to prenatal protein malnutrition. These animals, though calorically compensated, exhibited significant smaller axon diameters in the splenium while densities of both types of fibers were unchanged (Olivares et al., 2007). Differences observed in the current work are stronger than those detected by Olivares et al. (2007), probably due to less severity of the malnutrition model used in that study. In addition, we have presently increased the number of animals per group. Whether there was postnatal axon growth, which may compensate during lactancy the effects of prenatal malnutrition, remains unanswered but possible mechanisms involving development of myelin and axon glial sheaths are expected.

\section{CONCLUSIONS}

We conclude that malnourished animals show significant reductions in both total and partial callosal areas as well as in callosal perimeters. However, prenatal malnutrition did not modify the geometry associated to morphologic complexity of brain and CC, according to our calculations of fractal dimensions, finding an isometric reduction of callosal measurements. In fact, we found isometric reductions in any measures of brain parts, thus meaning that there are changes in the absolute values of the measurements obtained but not in the relationship between these measures. Therefore, these isometric variations do not affect inferences about relationships, and the causes of these geometric variations are changes in the size of the whole body (Bonner and Horn, 2000; Brown et al., 2000).

Finally, both myelinated and unmyelinated types of fibers decreased significantly in diameter, and a concomitant increase of unmyelinated fiber density, but not of myelinated axons, was observed. These findings suggest that cortico-cortical (interhemispheric) connections are vulnerable to prenatal malnutrition and this may affect interhemispheric conduction velocity, particularly in relation to visual connections (splenium).

\section{ACKNOWLEDGMENTS}

This work was partially supported by grant $\mathrm{N}^{\circ} 1030729$ from FONDECYT and grant FIV N¹21014019102004 from Faculty of Veterinary Sciences, University of Chile.

\section{REFERENCES}

ABOITIZ F (1992) Brain connections: interhemispheric fiber systems and anatomical brain asymmetries in humans. Biol Res 25: 51-61.

ABOITIZ F (1996) Does bigger mean better? Evolutionary determinants of brain size and structure. Brain Behav Evol 47: 225-245.

ABOITIZ F, IDE A, OLIVARES R (2003) The Cognitive Neuroscience of the Corpus Callosum. Corpus Callosum Morphology in Relation to Cerebral Asymmetries in the Postmortem Human. In: Zaidel E, Iacoboni M, editors. A Bradford Book The Mit Press Cambridge, Massachussets; pp: 33-49.

BONNER JT, HORN HS (2000) Allometry and Natural Selection in Scaling in Biology a volume in the Santa Fe Institute Studies in the Sciences of Complexity. Oxford University Press; pp: 60-73.

BROWN JH, WEST GB, ENQUIST BJ (2000) Patterns and Processes, Causes and Consequences. in Scaling in Biology a volume in the Santa $\mathrm{Fe}$ Institute Studies in the Sciences of Complexity. Oxford University Press; pp: $1-50$.

CANALS M, OLIVARES R, LABRA F, CAPUTO L, RIVERA A, NOVOA FF (1998) Measuring the fractal geometry of the bronquial tree in mammals. Rev Chil Anat 16:237-244.

FERRÁN M (2001) Análisis estadístico SPSS para Windows. Osborne McGraw-Hill; pp: 1-165.

FORBES WB, RESNICK O, STERN WC, BRONZINO JD, MORGANE PJ (1975) The effect of chronic protein malnutrition on trans-callosal evoked responses in the rat. Devl Psychobiol 8: 503-509.

FOWDEN AL, GIUSSANI DA, FORHEAD AJ (2006) Intrauterine programming of physiological systems: causes and consequences. Physiology (Bethesda) 21: 29-37.

GIL J, GIMENO M, LABORDA J, NUVIALA J (2006) Fractal dimension of dog kidney proximal convoluted tubuli sections by mean box-counting algorithm. Int J Morphol 24: 549-554.

GRESSENS P, MUAKU SM, BESSE L, NSEGBE E, GALLEGO J, DELPECH B, GAULTIER C, EVRARD P, KETELSLEGERS JM, MAITER D (1997) Maternal protein restriction early in rat pregnancy alters brain development in the progeny. Dev Brain Res 103: 21-35

GUNDERSEN HJ (1977) Notes on the estimation of the numerical density of arbitrary profiles. The edge effect. J Microsc 111: 219-223.

GUZMÁN M, MARTÍN MA, MORÁN M, REYES M (1993) Estructuras Fractales y sus Aplicaciones. Labor S.A. Barcelona; pp: 1-230.

HE $X$, SULLIVAN EV, STANKOVIC RK, HARPER CG, PFEFFERBAUM A (2007) Interaction of thiamine deficiency and voluntary alcohol consumption disrupts rat corpus callosum ultrastructure. Neuropsychopharmacol 32: 2207-2216.

KISELEV VG, HAHN KR, AUER DP (2003) Is the brain cortex a fractal? Neuroimage 20: 1765-1774.

KOLB B (1984) Functions of the frontal cortex of the rat: a comparative review. Brain Res Rev 8: 65-98

LEVITSKY DA, STRUPP BJ (1995) Malnutrition and the brain: changing concepts, changing concerns. J Nutr 125: Suppl 2212-2220.

MCMILLEN IC, ROBINSON JS (2005) Developmental origins of the metabolic syndrome: prediction, plasticity, and programming. Physiol Rev 85: 571-633.

MERLO A, ALBANECE AM, MIÑO J, GÓMEZ E, SAUBIDET A, MASCITTI T, INGRATA A, ALBANECE E (2002) Corpus callosum in the midsagital planum of magnetic resonance image: perimeter, surface and shape in relation with age and sex. Rev Chil Anat 20: 131-138.

MORGANE PJ, MILLER M, KEMPER T, STERN W, FORBES R, HALL J, BRONZINO J, KISSANE J, HAWRYLEWICZ J, RESNICK O (1978) The effects of protein malnutrition of the developing central nervous system in the rat. Neurosci Biobehav Rev 2: 137-230.

MORGANE PI, AUSTIN-LA FRANCE R, BRONZINO J, TONKISS J, DIAZ-CINTRA S, CINTRA L, KEMPER T, GALLER JR (1993) Prenatal malnutrition and development of the brain. Neurosci Biobehav Rev 17: 91-128.

NATIONAL RESEARCH COUNCIL, GUIDE FOR THE CARE AND USE OF LABORATORY ANIMALS (1996) National Institutes of Health, Bethesda; Publications 80-23 rev. 
NAVARRETE M, NÚÑEZ H, RUIZ S, SOTO-MOYANO R, VALLADARES L, WHITE A, PÉREZ H (2007) Prenatal undernutrition decreases the sensitivity of the hypothalamo-pituitary-adrenal axis in rat, as revealed by subcutaneous and intra-paraventricular dexamethasone challenges. Neurosc Letters 419: 99-103.

OLIVARES R, SOTO-MOYANO R, HERNÁNDEZ A. ABOITIZ F (2002) Mild protein prenatal malnutrition specifically affects development of the anterior corpus callosum. Rev Chil Anat 20: 159-163.

OLIVARES R, SOTO-MOYANO R, HERNÁNDEZ A, GIL J, GIMENO M, LABORDA J, ABOITIZ F (2007) Effect of mild protein prenatal malnutrition in the callosal splenium histology. Int J Morphol 25: 717721.

SOTO-MOYANO R, HERNÁNDEZ A, PÉREZ H, RUIZ S, CARREÑO P, BELMAR J (1993) Functional alterations induced by prenatal malnutrition in callosal connections and interhemispheric asymmetry as revealed by transcallosal and visual evoked responses in the rat. Exp Neurol 119: 107-112.

SOTO-MOYANO R, HERNÁNDEZ A, PÉREZ H, RUIZ S, CARREÑO P, ALARCÓN S, BELMAR J (1994) Clonidine treatment during gestation prevents functional deficits induced by prenatal malnutrition in the rat visual cortex. Int J Neurosci $76: 237-246$
SOTO-MOYANO R, ALARCÓN S, BELMAR J, KUSCH P, PÉREZ H, RUIZ S, HERNÁNDEZ A (1998a) Prenatal protein restriction alters synaptic mechanisms of callosal connections in the rat visual cortex. Int J Dev Neurosc 16: 75-84

SOTO-MOYANO R, ALARCÓN S, HERNÁNDEZ A, PÉREZ H, RUIZ S, CARREÑO P, KUSCH C, BELMAR J (1998b) Prenatal malnutritioninduced functional alterations in callosal connections and in interhemispheric asymmetry in rats are prevented by reduction of noradrenaline synthesis during gestation. J Nutr. 128: 1224-1231.

STERN WC, PUGH WW, JOHNSON A, MORGANE PJ (1983) Spontaneous forebrain neuronal activity in developmentally protein malnourished rats. Brain Res 285: 95-98.

WITELSON SF (1989) Handedness and sex differences in the isthmus and genu the human corpus callosum: a postmortem morphological study. Brain 112: 799-835.

ZIMMERBERG B, MICKUS LA (1990) Sex differences in corpus callosum: influence of prenatal alcohol exposure and maternal undernutrition. Brain Res 537: 115-122. 